\title{
Questões de gênero em Platão e Eurípedes: corpos antigos e gender performativity
}

\author{
Vânia Silva ${ }^{1}$ \\ ORCID: 0000-0002-3682-8171 \\ Gabriele Cornelli ${ }^{2}$ \\ ORCID: 0000-0002-5588-7898
}

\section{Resumo}

0 presente artigo propõe uma análise de dois textos clássicos da Antiguidade grega, As Bacantes de Eurípedes e a República de Platão, à luz da teoria contemporânea de gender performativity de Judith Butler. 0 conceito de gender performativity será apropriado para ilustrar analogamente, mesmo que de forma anacrônica, o quanto que o imaginário grego, apesar de temporalmente distante, pode nos apresentar - seja a partir do discurso filosófico, seja a partir do discurso literário da tragédia grega - bons exemplos para uma das teorias mais sofisticadas, diríamos, no campo dos estudos de gênero hoje. A proposta é a de mostrar de que modo o conteúdo desses dois textos nos permite compreender o debate contemporâneo da teoria crítica das identidades de gênero. Trata-se de identidades fixadas em atos performativos que conformam o gênero ao sexo anatômico, limitando-o a duas possibilidades: masculino ou feminino. Considerando o contexto histórico e as questões que são próprias do mundo grego antigo, a análise aqui proposta nos permitirá jogar luz, especialmente, nas estratégias que Platão e Eurípedes empreenderam no sentido de deslocar as normas de gênero constituídas na pólis. 0 exame dos textos permitiunos identificar que na antiguidade, mas também na contemporaneidade, mesmo que de forma diferente, as discussões das relações de gênero estão ajustadas, principalmente, pelo discurso político a respeito dessas relações.

\section{Palavras-chave}

Platão - República - Eurípedes - As Bacantes - Gender performativity.

1- Universidade de Coimbra, Coimbra, Portugal.

Contato: vania21santos@gmail.com.

2- Gabriele Cornelli, Universidade de Brasília, Brasília, DF, Brasil.

Contato: cornelli@unb.br 


\section{Gender issues in Plato and Euripides: ancient bodies and gender performativity}

\section{Abstract}

The current article draws on Judith Butler's gender performativity theory to analyse two classical text of Greek Antiquity - the Bacchae by Euripides and The Republic by Plato. The concept of gender performativity will be used to illustrate analogously even anachronically, how much the Greek imaginary, in spite of being temporally distant, can fruitfully contribute to, what we would identify as one of the most sophisticated contemporary theories in contemporary gender studies, both as this imaginary emerges from the literary discourse of the tragedy or the discourse of philosophy. This will allow us to show how the two above mentioned texts can contribute to the contemporary debate on the critical theory of gender identity, as these are fixed in performative acts that make gender conform to anatomic sex, limiting gender to the two possibilities of masculine or feminine. Considering the historical context and the question that are specific to the world of Ancient Greece, our analysis will permit us to cast light, in particular, on the strategies that Plato and Euripides drew on to disrupt the gender norms of the polis. Examining the texts allows us to argue that in antiquity, as well as in the contemporary world, albeit in different ways, discussions of gender relations are fitted primarily by the political discourse regarding these relations.

\section{Keywords}

Plato - Republic - Euripides - The Bacchae - Gender performativity.

\section{Introdução}

A tradição dos estudos feministas, que se confunde com aqueles hoje de forma quiçá mais politicamente correta chamados de gender studies, ${ }^{3}$ entrega-nos uma concepção das categorias do sexo como produções de uma determinada composição de poder que pretendem - retoricamente - "criar o efeito de sua originalidade, naturalidade, inevitabilidade" (BUTLER, 1999, p. xxviii [BUTLER, 2010, p. 9]). Uma distinção binária dos sexos, portanto, que deseja fixar o que é feminino de um lado preciso de uma pretensa dicotomia entre masculino e feminino. A construção dessa oposição binária obedece à intenção de relegar o feminino ao lugar da paranomía com respeito ao ponto de vista empoderado do masculino, que se autoatribui à função de nómos. A naturalização dos papéis sexuais, portanto, seria o resultado retórico de uma precisa estratégia de poder. É nesse sentido que Butler pode afirmar que -

3- 0 conceito ganhou grande visibilidade na década de 1980 com a ressistematização feita por Joan Scott (1995) no artigo Gênero - uma categoria útil de análise histórica, originalmente publicado em 1986. Contudo, antes dela, importantes teóricas usaram o termo, como Gayle Rubin (1975) e Nancy Chororow (1979). 
nesta lógica binária do discurso sobre os sexos - "ser mulher é uma indisposição natural" (BUTLER, 1999, p. xxix [BUTLER, 2010, p. 8]).

A economia destas páginas não nos permite examinar com o cuidado que certamente mereceria nem sequer a mais recente tradição da interpretação feminista de Platão, desde o célebre ensaio de Vlastos (Was Plato a feminist?, 1994), em boa parte superado pelos estudos de Julia Annas (1996), por meio da leitura da diferença sexual de Luce Irigaray (1994), Giulia Sissa (1990), Sylviane Agacinski (1998) e Adriana Cavarero (1990, 1995), até as mais recentes abordagens de matriz foucaultiana e derridiana (SANFORD, 2010). Basta anotar que o tema é polêmico e o debate intenso, como demonstram os diferentes resultados hermenêuticos aos quais as estudiosas feministas de Platão acabam chegando.

0 que mais nos interessa é a hipótese de que a cultura grega antiga, e Platão nela, está bastante distante dessa definição da dicotomia sexual homem/mulher como a conhecemos em nossa modernidade, retoricamente fundamentada no conceito natural/ biológico de sexo. ${ }^{4}$ É Sanford (2010) a levantar essa hipótese em seu recente livro intitulado significativamente Plato and sex: prova disso seriam exatamente as repetidas proibições aos homens de se portarem como mulheres em República, sugerindo haver certa commutability entre os sexos e que a definição do que seja homem ou mulher dependerá mais precisamente de uma série de características que, teórica e praticamente, poderão ser assumidas também por homens. Pela verdade, já Vlastos havia percebido certa denaturalização (ou melhor, ainda-não-naturalização) da diferença sexual nas páginas platônicas, quando afirma, com relação às características que definem a mulher: "Platão não está dizendo que existem, na espécie das fêmeas, características como uma natureza permanentemente fixa e invariante: não existe referência à natureza das mulheres [na República]" (VLASTOS, 1994, p. 18).

Se, por um lado, não é, certamente, apropriado falar das relações de gênero do mundo grego nos termos dualista contemporâneo de sexo-gênero, ${ }^{5}$ por outro, ao lermos os textos antigos salta aos olhos o modo vertical de organizar as relações entre homens e mulheres. Hierarquização que tem no homem o imperativo de ordenar a economia do poder e do status dos indivíduos. Tampouco não nos é estranha a conhecida importância dada pelos gregos à reprodução dos seres humanos, o que não raras vezes limitou o papel das mulheres ao da reprodução, ao de simples recipientes. 0 corpo receptáculo tornou-se o seu destino. ${ }^{6}$ Com essas observações em mente, analisaremos dois textos, As Bacantes de Eurípedes e a República de Platão. Veremos em que medida esses textos nos apresentam um caminho outro. Uma alternativa na qual as relações de gênero podem ser diferentes tanto daquelas antigas quanto das nossas contemporâneas.

\footnotetext{
4- Uma exceção na modernidade é certamente a descrição da sexualidade humana de Freud, que é explicitamente aproximada àquela do éros platônico. Vejam-se, por exemplo, os Três ensaios sobre a teoria da sexualidade, nos quais Freud afirma que as linhas gerais de sua teoria da sexualidade coincidem com aquelas do éros do "divino Platão". Para um exame aprofundado dessa relação entre os dois conceitos, confira Sanford (2010, cap. 3).

5- Cf. o livro editado por Thomas K. Hubbard (2014) A Companion to Greek and Roman Sexualities.

6- A análise desse aspecto de modo restrito à obra platônica é bastante vasta e tem como principal referência a discussão levantada no Timeu sobre o terceiro elemento: Chõra. Lucy Irigaray (1994) e Judith Butler (2011) dedicaram-se ao estudo desse livro. No campo dos Estudos Clássicos e sua fusão com os estudos de gênero, encontramos trabalhos como o de Emanuela Bianchi (2006) e Panayotov (2011).
} 


\section{Política de enfrentamento dionisíaco}

A cultura grega, precisamente a ateniense, parece-nos, orienta-se mais ao que contemporaneamente com Butler $(2010,2011)$ chamamos gender performativity, isto é, atos performativos deliberados, que podem se desdobrar tanto numa desnaturalização quanto numa reidealização das normas de gênero. A inteligibilidade cultural da performance é que dirá se o ato subverte as normas ou se já foi cooptado pelo processo de imitação de atos, que devido a sua repetição exaustiva, busca normatizar, conformar e identificar a matéria à performance ou, em outras palavras, a anatomia do sexo à identidade de gênero. Assim, tomaremos o conceito de gender performativity para ilustrar analogamente, mesmo que de forma anacrônica, o quanto que o imaginário grego, apesar de temporalmente distante, pode nos apresentar - seja a partir do discurso filosófico, seja a partir da dramaturgia bons exemplos para uma das teorias mais sofisticadas, diríamos, no campo dos estudos de gênero hoje.

Lessa (2010) nota que na cultura grega os papéis de gênero, mesmo que se tentasse idealizá-los no plano das normas e atos identitários, não eram plenamente satisfeitos nas suas expectativas; exemplo disso é o conjunto daquilo que é denominado de as mulheres bem-nascidas. Essas aprendiam um conjunto de regras as quais deviam seguir para manter o status. Contudo, como bem observa Lessa, as vestimentas e adereços das mulheres bemnascidas por vezes confundiam-se com aqueles que lembravam a deusa do desejo, Afrodite, o que poderia ter gerado um contrassenso ver uma Melissa com vestes de Afrodite. Outro detalhe que marca a relação difusa nas fronteiras entre o masculino e o feminino, no contexto da antiguidade clássica, é a existência de um tipo de vestimenta feita de chitón, que poderia ser tanto usada por homens quanto por mulheres e isso confere "um signo a mais de permeabilidade e complementariedade entre os espaços masculinos e femininos" (LESSA, 2010, p. 38).

Precisamente essas relações não deixaram de ser exploradas pelos dramaturgos. É bem conhecido no teatro grego o fato da tragédia marcar um aspecto político, por tratar de questões preeminentes para os espectadores. No estilo de Eurípedes, por exemplo, a marca política introduz em "peças não políticas cenas, ou ditos, que sentenciam sobre o resto e que parecem fazer eco de problemas então actuais” (ROMILLY, 1999, p. 103). É nesse terreno, portanto, que primeiro armaremos nosso palco para pensar gender performativity nesse período.

No teatro de Eurípedes aparece um clássico exemplo da noção de atos performativos de gênero. Com efeito, n'As Bacantes, Dionísio é representado como um deus cuja performance de gênero é ambígua. Esse deus da desmedida - numa leitura nietzschiana - comporta performances que vão além dos limites sociopolíticos postos à anatomia. Ele realiza uma verdadeira paródia e mostra-se consciente de que a própria origem daquilo que ele imita e performa é já uma cópia. Portanto, brinca com as normas por não ter uma definição fixa de gênero e por saber que não há um ideal a que se prender. Como observa Romilly, Dionísio brinca e joga com as imagens:

Inicia a peça sob uma falsa identidade, que manterá até ao fim: faz-se passar por um sacerdote lídio e só o espectador está dentro do segredo. Também é preciso ver como ele troça de Penteu! 
Escarnece-o por meio de palavras; multiplica as palavras ambíguas; irradia superioridade perante a ignorância do outro. E quando Penteu o manda prender, atar, muda simplesmente de forma. Este mestre da ilusão torna-se então num touro; e, enquanto o homem se consome querendo amarrar o touro, o deus olha com uma ironia divertida: 'e eu [...] estava sentado e tranquilo, a olhar' (ROMILLY, 1999, p. 129-130).

Dionísio observava Penteu enfurecido ao mesmo tempo em que brincava de transformar o corpo. Na peça, o personagem de Penteu é um homem a que foi posto em uma posição de governante, ou seja, em uma posição de poder. Uma das características do seu modo de governar é a aversão a toda mudança de norma já estabelecida. ${ }^{7}$ Penteu não apenas repulsa as performances de Dionísio como a de todos que o acompanha: as mulheres que abandonam as casas e mesmo Cadmo e Tirésias, que em sua velhice não deixam de honrar o deus dos tamboris e das danças. Os seus atos são políticos e ele faz questão de dar mostras de sua soberania. Penteu arroga para si o poder de decidir quem vive, como se vive e quem morre. Deixemos que os próprios versos de Penteu elucidem essa dinâmica do que contemporaneamente denominamos, com Foucault e Agamben, de biopoder, ${ }^{8}$ esse que nos é tão familiar.

Penteu - Quantas eu já apanhei, os meus guardas conservam-nas a bom recato nas prisões públicas, de mãos atadas. As que faltam, dar-lhe-eis caça para fora das montanhas. [Refiro-me a Ino e Agave, aquela de quem Équion me gerou, e à mãe de Actéon, Autónoe]. Apertá-las-ei em redes de ferro, para em breve pôr termo a estas vis bacanais.

[...].

Penteu - Dizem que chegou aí um tal estrangeiro, um mago com encantamentos, vindo do país da Lídia, de cabelos perfumados, com louros caracóis, com o fascínio purpúreo de Afrodite nos olhos, que dia e noite se mistura com as moças, acenando-lhes com os seus mistérios jubilosos. Se eu o apanho dentro destes tectos, acabarei com seu bater de tirso e o sacudir da cabeleira: arranco-lhe o pescoço para fora do corpo. (EURÍPIDES, 2011, v. 227-41 [EURIPIDES, 2013, v. 227-41]).

\footnotetext{
7- Aqui a noção de norma será tomada na acepção dada por Butler (2004, p. 41), segundo sua definição, "a norm is not the same as a rule, and it is not the same as a law. A norm operates within social practices as the implicit standard of normalization. Although a norm may be analytically separable from the practices in which it is embedded, it may also prove to be recalcitrant to any effort to decontextualize its operation. Norms may or may not be explicit, and when they operate as the normalizing principle in social practice, they usually remain implicit, difficult to read, discernible most clearly and dramatically in the effects that they produce".

8- Foucault (2008) dedicou parte de suas investigações ao tema do governo, do Estado e do poder. Investigou como estas estruturas se transformaram ao longo dos séculos culminando na intensificação do controle da vida e da morte, prática essa já presente desde o século XVI e coincide com o nascimento das instituições jurídicas e com uma nova forma de governar desassociada do poder do rei. Agamben (2010) retoma Foucault em muitas de suas análises políticas, no livro Homo Sacer: o poder soberano e a vida nua traz a discussão sobre a soberania e o biopoder, nele, Agamben radicaliza a análise segundo a qual a política é consumada na própria soberania sobre a vida e a morte do corpo, diz o filósofo: "até mesmo o conceito de 'corpo', bem como aqueles de sexo e sexualidade, já está desde sempre preso em um dispositivo, ou melhor, é desde sempre corpo biopolítico e vida nua, e nada, nele ou na economia de seu prazer, parece oferecer-nos um terreno firme contra as pretensões do soberano" (AGAMBEN, 2010, p. 181-182). 0 filósofo Achille Mbembe (2017), no livro Políticas da Inimizade, apresenta em suas análises forte influência das teorias de Foucault e de Agamben. Mbembe ao discutir sobre o biopoder estabelece relação entre "0 Estado de excepção e 0 Estado de sítio" demonstrando como estas formas de governar estão, em última instância, diretamente relacionadas com o controle sobre a vida e a morte de determinados indivíduos, daí advém a formulação do seu conceito de necropolítica (MBEMBE, 2017, p. 115).
} 
Para o biopoder já não importa a vida, mas alguns tipos de vida. As vidas que não importam são preteridas à abjeção. 0 extermínio desses corpos abjetos, incoerentes e inteligíveis é prática política comum. Sendo mais uma demonstração para afirmar quem institui a norma e a coerência por meio, obviamente, da força e do medo. Assim, as vidas daqueles que importam, ou seja, de quem carrega nos seus corpos a normalização do discurso soberano, esses terão suas vidas poupadas, não porque elas importam de fato, mas porque elas ajudam a manter a soberania de quem tem a força e o poder para ditar quais atos performativos devem ser realizados. Desse modo, o espetáculo do horror e da morte servem como landscape a ser apreciada. Ora, "não tenhas dúvidas! Sentava-me, silencioso, debaixo dos abetos” (EURÍPIDES, 2011, v. 816 [EURIPIDES, 2013, v. 815-816]).

E o que acontece quando Dionísio cansa-se da paródia e passa a intervir dentro da política? A punição que Penteu recebe é como sabemos a de se travestir daquilo que lhe é repugnante, uma bacante. Ele não só se traveste como também a performa.

Diónisos - reveste então o teu corpo de uma túnica de linho

Penteu - Que quer isso dizer? De homem vou passar a mulher?

Penteu - Que veste é que dizes que vais enfiar no meu corpo?

Diónisos - Da tua cabeça farei pender uma longa cabeleira.

Penteu - E qual é a segunda característica do meu adereço?

Diónisos - Uma túnica até aos pés. Na cabeça terás uma fita. (EURÍPEDES, 2011, v. 821-834

[EURIPIDES, 2013, v. 821-834]).

Rendido a Dionísio, Penteu, em um estado de desvario, não apenas troca sua roupa ${ }^{9}$ como também sua identidade "de homem do poder". Ele permite sacudir-se como uma bacante (EURÍPEDES, 2011, v. 930-931 [EURIPIDES, 2013, v. 930-931]), tem uma performance de bacante. Sobre o detalhe da sua túnica em seu tornozelo esquerdo, o dramaturgo apresenta sua expressão corporal: "olhando por cima do ombro para a perna esquerda”, Penteu diz a Dionísio “deste lado, a túnica cai certa sobre o calcanhar" (EURÍPEDES, 2011, v. 937-938 [EURIPIDES, 2013, v. 937-938]). Dionísio, atento a sua valorização e a sensibilidade para o detalhe estético, manifesta ironicamente felicitando-o por sua mudança no "estado de espírito" (EURÍPIDES, 2011, v. 944 [EURIPIDES, 2013, v. 944]). É assim que o estrangeiro efeminado conseguiu vingar-se daqueles que não honram a sua divindade; porém, fez mais do que vingar-se: ele conseguiu romper com o núcleo que sustentava aquela soberania. A morte de Penteu simboliza a desestruturação

\footnotetext{
9 - No perspectivismo ameríndio, segundo Eduardo Viveiro de Castro (1996, p. 423), há uma concepção fundida à noção de que "a forma manifesta de cada espécie é um mero envelope (uma 'roupa') a esconder a forma [de gente] humana". A "forma manifesta" é o corpo. 0 que Viveiros de Castro chama de "roupa" é a noção maleável daquilo que torna o corpo variável, pois cada um vestirá a roupa de sua "tribo", porém mesmo isso não fixará os atributos, pois é "uma roupa trocável e descartável", o que permitiria a permeabilidade e a metamorfose. É importante notar que na cosmologia ocidental, é o corpo que está aliado à natureza e é ele que une os seres; na cosmologia ameríndia, 0 inverso acontece, o corpo é aquele que diferencia os seres. Para os ameríndios, de acordo com Viveiros de Castro, há somente uma cultura e variadas e numerosas naturezas o que implica a tese de que a "diferença é dada pela especificidade dos corpos" (VIVEIRO DE CASTRO, 1996, p. 437). Os corpos são um "conjunto de afecções ou modos de ser que constitui um habitus" (VIVEIRO DE CASTRO, 1996, p. 438).
} 
da família tal como foi significada na Grécia antiga. ${ }^{10}$ Cadmo é "privado da descendência masculina” (EURÍPIDES, 2011, v. 1034-35 [EURIPIDES, 2013, 1034-35]). As mulheres, mesmo que sob o efeito embriagante de Dionísio, realizam um ato performativo insurreto do qual se orgulham e percebem os limites aos quais são fixadas. Elas entendem que seus corpos podem mais do que as constrições ditas pela pólis.

Agave - Bem podes, ó pai, glorificar-te acima de todos, por teres dado o ser àquelas que são, de longe, as filhas mais valentes de entre os mortais. A todas eu incluo, e a mim em especial, eu que abandonei a lançadeira junto do tear e me elevei a mais altos feitos, a caçar feras pelas minhas mãos. (EURÍPIDES, 2011, v. 1231-39 [EURIPIDES, 2013, v. 1231-1239]).

Como foi dito, um ato performativo de gênero pode tanto reafirmar uma norma quanto, a partir dele, fazer proliferar outros modos. É nesse sentido amplo que o desdobramento foi, então, subversivo. 0 foi também porque esse trânsito, essa desobediência à forma idealizada dos gêneros, quando externalizada no campo político da cidade, tem efeitos que são morais, éticos e, obviamente, políticos. A gender performativity das bacantes mesmo que de forma transitória, dado que ocorria dentro de um espaço temporal dos ritos dionisíacos, apontava para um caminho de suspensão daquele que era o modelo do sistema político de Atenas dos séculos V e IV, ou seja, um paradigma que em sua prática subordinava as mulheres, sobretudo, aos interesses reprodutivos da pólis. Desse modo, para as mulheres atenienses não havia grandes possibilidades para além de performar 0 ato de gestação de humanos, ato esse legitimado dentro do casamento. ${ }^{11}$ De acordo com Daraki (1994, p. 181), "le mariage civique réglemente un seul et étroit domaine: la reconduction de la cité politique”. A questão que se poderia colocar é: qual orientação de recondução política é realizada? E para qual caminho se quer conduzir a política na pólis?

\section{Justiça de gênero}

Vejamos agora como isso ocorre no discurso filosófico de Platão, ou seja, como o exercício de pensar uma cidade justa conduziu-o a arquitetar propostas tão subversivas para os costumes de seu tempo. Comecemos por apresentar essas propostas que permutam as regras do jogo das identidades de gênero já naturalizadas, mesmo aos seus pares.

É conhecida a polêmica que Platão gera no livro V da República. A inclusão das mulheres na classe dos guardiões não tem fácil aceitação por parte de seus interlocutores e nem por parte das diversas gerações de platonistas ao longo desses 2500 anos. ${ }^{12}$ No diálogo, a dificuldade dos interlocutores de Sócrates, de pensar as relações de gênero tal

\footnotetext{
10 - Vernat (1992) observa que apesar de, no século V a.C, havia muitas formas de união: "a cidade democrática se esforça por privilegiar uma forma de união e excluir as demais" (VERNAT, 1992, p. 52). Institui-se uma forma de casamento e um modelo de esposa que tem como função principal a procriação.

11- Acerca da posição das mulheres no campo jurídico da pólis, conferir o artigo In Defense of Medea: a legal approach to Euripides (LEÃO, 2011). 12- Natalie Harris Bluestone, no livro Women and the Ideal Society - Plato's Republic and Modern Myths of Gender (1987), analisa a recepção dos platonistas quanto ao livro V da República no período de 1870 a 1970. Em suas análises, ela identificou mudanças a respeito das propostas no decorrer no tempo, contudo observou que a recepção, de modo geral, concentrou-se na crítica negativa às propostas, assim como ganhou um tom cético, jocoso e também conservador.
} 
como Platão sugere, encontra-se na concepção segundo a qual a diferença sexual entre homens e mulheres não apenas é compreendida como uma diferença no nível biológico e anatômico, mas também o é no nível ontológico. É ainda pressuposto que cada um dos sexos anatômicos cumpra atos performativos de gênero conforme sua anatomia. A questão que se coloca é aquela segundo a qual o conceito de gênero parece permanecer nos limites fixados de dois sexos e dois gêneros.

Assim, os gêneros constituídos culturalmente são harmonizados aos sexos. Um exemplo dessa conformidade é a associação de uma pessoa com vagina à uma performance de mulher, tal como a sociedade qualifica essa performance. Há aqui um efeito mimético, em que um corpo com vagina corresponderia a uma mulher, ou seja, é uma pessoa do sexo feminino, mas se sabe que essa associação simplifica a diversidade de performances que um corpo com vagina ou com pênis pode ter. A questão problematizadora é: se o sexo anatômico é em número de dois, ${ }^{13}$ por que as identidades de gênero precisam permanecer em igual número? Se esse for o caso, ou seja, se o "sexo é, ele próprio, uma categoria tomada em seu gênero, não faz sentido definir o gênero como a interpretação cultural dos sexos" (BUTLER, 2010, p. 25 [BUTLER, 1999, p. 11]). Essa é a crítica de Butler à noção de gênero assentada na teoria da construção cultural. Segundo a filósofa, essa teoria tem como pressuposto primeiro: i) a diferença do sexo anatômico é inquestionável, pois se legitima a partir do discurso da biologia; e, segundo ii) gênero é o que se manifesta, em um corpo sexuado, a partir das experiências e significações culturais.

0 que não é percebido, de modo geral, é o fato de os atos performativos serem efeitos de um discurso cultural exaustivamente repetido com finalidade de manter a dominação de um grupo sobre o outro. A imitação desse gênero verdadeiro é incentivada e realizada pelos próprios indivíduos que desejam o reconhecimento dentro do grupo, o que se generalizará dentro do corpo político e social. Nesse terreno, de modo afiado, Platão e Butler - de forma não menos brilhante - fazem a crítica à estrutura política que presume e define os códigos de inteligibilidade pousando-os no campo seguro de uma ontologia essencialista e da natureza, retirando todo o seu caráter político.

Platão começa por dizer que as fêmeas dos cães fazem tudo em comum com os machos e isso é possível, segundo ele, porque dentro da espécie não é limitado à fêmea o cuidado com a cria. Ora, se se quer as mulheres nos mesmos cargos que os homens, então é preciso que a elas seja dada a mesma educação (PLATÃO, 1949, 451e [PLATO, 1997, 451e]). Mas a natureza diferente não é um dos requisitos para atribuir funções diferentes? Como então permitir que mulheres façam o mesmo que os homens se eles são constituídos de naturezas diferentes? As funções não devem ser compatíveis com a natureza de cada um?

\footnotetext{
13- Confira Anne Fausto-Sterling (1993), no artigo The Five Sexes: Why Male and Female are not Enough (1993), no qual ela levanta 0 importante dado médico e biológico, segundo o qual há muitos graus antômicos entre o macho e a fêmea. Segundo a bióloga, na literatura médica standard é utilizado o termo intersexo, que por sua vez dispõe em três grupos todos os humanos nascidos, são eles: feminino, hermafrodita e masculino. Contudo, Fausto-Sterling reivindica, a partir de estudos biológicos, a subdivisão do grupo hermafrodita, devido à sua complexidade. Os grupos seriam: hermes, mermes e fermes. São dispostos de acordo com as semelhanças e diferenças que apresentam. Para Fausto-Sterling (1993, p. 21), o sexo é um "infinitely malleable continuum that defies the constraints of even five categories".
} 
Não percamos de vista que os temas discutidos na República têm o objetivo de definir o que é justiça, ${ }^{14}$ elucidar as características de uma cidade justa e apresentar um paradigma que possa realizar o projeto dessa cidade. Desse modo, podemos entender que as proposições de Platão à classe das mulheres visam o bem ao conjunto inteiro da polis, incluindo as mulheres.

Sócrates - Ora, presentemente estamos a modelar, segundo cremos, a cidade feliz, não tomando, mas à parte um pequeno número, para os elevar a esse estado, mas a cidade inteira. (PLATÃo, 1949, 420c [PLATO, 1997, 420c]).

[...].

Sócrates - Deve, portanto, observar-se, se estabelecemos os guardas tendo em vista proporcionarlhes o máximo de felicidade, ou se se deve ter em consideração a cidade inteira, para que ela a alcance, e forçar os auxiliares e os guardiões a proceder assim e persuadi-los, a fim de que sejam os melhores artistas no seu mester, e assim em todas as profissões; deste modo, quando toda a cidade tiver aumentado e for bem administrada, consentir a cada classe que participe da felicidade conforme a sua natureza. (PLATÃO, 1949, 421c [PLATO, 1997, 421c]).

Ao propor uma reorganização na configuração política e social das relações na kallipolis, Platão desloca o próprio paradigma das relações de gênero, colocando-os sob outro ângulo: nesse os homens e as mulheres assumiriam quase que uma alteridade radical aos olhos dos atenienses de seu tempo.

Sócrates - Mas talvez muito do que agora disse pareça ridículo, e contrário aos costumes, se se executar o que declarámos.

Sócrates - Qual das coisas notas tu que seja a mais ridícula? É evidente que serão as mulheres nuas a fazer ginástica com os homens nas palestras - não só as novas, mas também as que são positivamente mais velhas, tal como os velhos nos ginásios quando, cheios de rugas e pouco agradáveis à vista, mesmo assim gostam de praticar a ginástica?

Gláucon - Sim, por Zeus! Pareceria bem ridículo, pelo menos nas condições actuais. (PLATÃo, 1949, 452a-b [PLATO, 1997, 452a-b]).

A proposta de alteração que Platão faz das relações de gênero é possível porque ele deixa de olhar para anatomia do sexo como um limite das performances dos indivíduos. Ele põe corpos sexuados de homens e mulheres no mesmo plano, e é desse plano que parte para uma construção política da organização das identidades de gênero. Obviamente, usamos aqui os termos contemporâneos para defınir o movimento (não fácil) de Platão na primeira onda ${ }^{15}$ de sua proposta de inclusão das mulheres no governo da cidade. Como ele mesmo sublinha:

14- Cf. [PLATÃO, 1949, 472b] Plato (1997, 472b): "Ora é preciso recordar em primeiro lugar que nós chegámos a este ponto para indagarmos a natureza da justiça e da injustica".

15 - No livro V da República, Platão esboça três propostas políticas que completam o projeto da Kalipollis. Dado o grau de dificuldade e novidade dessas propostas, o filósofo usa a metáfora marinha, denominando-as de ondas. Platão apresenta cada uma das propostas conforme 0 grau de complexidade de cada uma, respectivamente. Platão diz: "É que talvez não saibas que depois de eu ter escapado a custo a duas vagas estás agora a erguer a terceira, que é mais alta e mais árdua de todas" (PLATA0, 1949, 472a [PLAT0, 1997, 472a]). A primeira onda diz respeito à 
Sócrates - Diremos que escapámos como se fosse a uma onda, de tal maneira que não ficámos de modo algum submersos, ao estabelecer que devem cuidar de tudo em comum, os guardiões e as guardiãs, mas a própria coerência do discurso proclama a possibilidade e utilidade do plano. (PLATÃO, 1949, 457b-c [PLATO, 1997, 457b-c]).

Raramente ocorreu na história do pensamento ocidental uma ocasião como esta, em que foi possível pensar politicamente os atos performativos de homens e mulheres. 0 comum é confiná-la ao sexo anatômico junto com tudo o que isso significaria, como, por exemplo, a imperiosidade da maternidade e/ou pensar a anatomia feminina como corporalmente mais débil em termos de força física e ter isso como um limite de participação no espaço da ágora para as mulheres. Nada mais significativo para esse rompimento do que as palavras do filósofo:

Sócrates - Se se evidenciar que, ou o sexo masculino, ou o feminino, é superior um ao outro no exercício de uma arte ou de qualquer outra ocupação, diremos que se deverá confiar essa função a um deles. Se, porém, se vir que a diferença consiste apenas no facto de a mulher dar à luz e o homem procriar, nem por isso diremos que está mais bem demonstrado que a mulher difere do homem em relação ao que dizemos, mas continuaremos a pensar que os nossos guardiões e as suas mulheres devem desempenhar as mesmas funções. (PLATÃO, 1949, 454d-e [PLATO, 1997, 454d-e).

Para dar conta da ideia de que "não há na administração da cidade nenhuma ocupação, própria da mulher, enquanto mulher, nem do homem, enquanto homem, mas as qualidades naturais são distribuídas de modo semelhante em ambos os sexos" (PLATÃo, 1949, 455d [PLATO, 1997, 455d]). Platão diz que é preciso distinguir a que se referem quando estão a falar de physis naquele diálogo. Ele começa a esboçar o argumento, talvez o mais importante, para sua defesa dos direitos sociais e políticos das mulheres. Primeiro diz que é preciso diferir o que se denomina de natureza diferente e de natureza própria. Dessa distinção ele parte para uma questão bastante arguta, a saber: é a natureza dos calvos e dos cabeludos a mesma? Se se assume que a diferença percebida entre o calvo e o cabeludo não permite a eles próprios transitar dentro de espaços posicionais, então a proibição consiste apenas em fazer dessa diferença física uma barreira ilusória para a mobilidade. Porém, se é admitido que calvos e cabeludos têm potencialmente as mesmas capacidades naturais para executarem uma mesma função, a barreira feita com base na diferença física, uma diferença apenas no plano sensível, não se aplica mais.

Sócrates - É-nos lícito, ao que parece, perguntar a nós próprios se a natureza dos calvos e dos cabeludos é a mesma, e não contrária, e, depois de assentarmos em que é contrária, se os calvos forem sapateiros, não consentir que os cabeludos o sejam, e se, por sua vez, o forem os cabeludos, proibi-los aos outros.

Glaúcon - Ridículo, não há dúvida!

inclusão social e política das mulheres, da classe dos guardiões, no governo. Na segunda onda Platão propõe uma organização social baseada na comunidade de mulheres e crianças, da classe dos/as guardiões/ãs; na terceira e última onda, considerada também a mais difícil, Platão apresenta 0 argumento segundo 0 qual o governante deve ser filósofo. 
Sócrates - Ridículo, na verdade, por outra razão: é que não supusemos então uma natureza igual ou diferente, mas apenas observámos aquela espécie de diferença e semelhança que tem por alvo as ocupações. Diziamos, por exemplo, que o médico e aquele que tem vocação para a medicina tinham a mesma natureza. Ou não achas?

Glaúcon - Acho, sim.

Sócrates - Mas, o médico e o carpinteiro têm uma natureza diversa. (PLATÃ0, 1949, 454c-d [PLATO, 1997, 454c-d]).

0 exemplo permite concluir que homens e mulheres, sendo dotados da mesma natureza, têm as mesmas capacidades, se se lhes der a mesma educação e instrução. Em nada a natureza os difere: a diferença está apenas na anatomia e isso não deve impedir as mulheres de desenvolverem outras capacidades que não aquelas que os costumes lhes outorgaram.

A isso, Simone de Beauvoir acrescentaria: mesmo que se conclua o fato da anatomia do sexo das mulheres lhes impor algum limite é preciso definir:

O corpo a partir da existência [assim], a biologia torna-se uma ciência abstrata; no momento em que o dado fisiológico (inferioridade muscular) assume uma significação, esta surge desde logo como dependente de todo um contexto. (BEAUVOIR, 2015, p. 76 [2010, p. 75]).

A discussão da inclusão das mulheres na classe dos guardiões teria também esse intento, o de fazer perceber que individualmente tanto homens quanto mulheres dentro dos seus respectivos conjuntos se diferenciam entre si, ou seja, os homens se diferenciam entre si, as mulheres não são todas iguais e o mesmo ocorre entre ambos os sexos. Contudo, essas diferenças, como já vimos, não são per si argumentos para a exclusão de um ou outro sexo em determinadas funções.

Sócrates - Mas há como julgo, e como diremos, umas mulheres dotadas para a medicina e outras não, umas para a música, e outras por natureza amusicais.

[...].

Sócrates - E que espécie de opinião tens sobre este assunto?

Glauco - Sobre qual?

Sócrates - Ser de opinião que um homem é melhor, e outro pior. Ou achas que são todos iguais? Glauco - De modo algum. (PLATÃo, 1949, 455e-456d [PLATO, 1997, 455e-456d]).

Uma cidade onde há leis justas para todas as pessoas trataria de perceber essas diferenças e usá-las para o bem comum. Haveria tanto excelentes médicas, quanto excelentes médicos, bem como excelentes guardiãs e excelentes guardiões. Todavia, organizar esse trabalho é função de uma justa política dos governantes da pólis. Trata-se não apenas de proporcionar às mulheres as mesmas oportunidades no nível intelectual, mas também as condições práticas para o desenvolvimento de suas capacidades como o todo. Na continuidade, Platão diz que: 
[...] tomarão conta das crianças que forem nascendo as autoridades para esse fim constituídas, quer sejam homens ou mulheres, ou uns e outros - uma vez que os postos de comando são comuns a homens e mulheres. (PLATÃO, 1949, 460b [PLATO, 1997, 460b]).

0 que é considerado por seus interlocutores "facilidades" às mulheres (PLATÃo, 1949, 460d [PLAT0, 1997, 460d]), Platão vê como necessário para o seu desenvolvimento e para a realização da kallipolis.

Mari Mikkola (2016), em seu recente trabalho The Wrong of Injustice, não faz referência direta à República, contudo, possivelmente, teria um frutífero diálogo com o filósofo ateniense. A filósofa mostra como ainda hoje persistem modos de injustiças cometidos contra as mulheres em grande escala apenas por serem mulheres. Injustiças que são melhores conformadas dentro de um processo daquilo que ela nomeia de dehumanization - ou no vocabulário de Butler (2011) e Julia Kristeva (1982), abjeção. Dehumanization é uma série de violência acometida às mulheres, que retira dela o valor de pessoa. As violências, por vezes, constituem-se em impedimento para as mulheres de participarem com oportunidades iguais junto aos homens na vida social. Formas gerais de injustiças como a dominação, a discriminação e a opressão trazem junto a si as variadas formas específicas de injustiças como o sexismo (feminicídio, violência física e psicológica, violência sexual), o racismo, a homofobia, o preconceito social, dentre tantas outras. Mikkola coloca nesse contexto de dehumanization a interdição às mulheres, dentro de um contexto global, do acesso à educação. ${ }^{16}$

\begin{abstract}
Considere a prática de impedir às mulheres o acesso à educação. Esse impedimento tem impactos sobre uma ampla gama de interesses básicos de bem-estar e constitui um retrocesso indefensável para tais interesses, a indefensibilidade é parcialmente explicada em termos de arranjos sociais patriarcais subjacentes. É claro que, nesse caso, tais arranjos sociais também prejudicam os interesses do bem-estar das mulheres. Esses impedimentos são geralmente baseados em certos fatos supostos sobre as mulheres e sua natureza. Ao fazê-lo, o tratamento claramente falha em reconhecer que não há nada intrínseco nas mulheres que as torne incapazes de serem educadas ou de escolherem seus próprios planos de vida - ele, simplesmente, obtém os fatos relevantes sobre as mulheres enquanto humanas. Além disso, o impedimento é indefensável por ser injustificável e indesculpável. É injustificável em bases epistêmicas: ou seja, é empiricamente errado pensar que há algo sobre a natureza e as habilidades naturais das mulheres que justificaria proibi-las de receberem educação. (MIKKOLA, 2016, p. 170-71).
\end{abstract}

As propostas de Platão para as mulheres podem ser compreendidas hoje, sobretudo, como um modo de combate à política feita do seu modo mais vil, uma política que exclui e segrega. Política que, eivada pelo seu caráter corruptível, é feita para poucos, seja ela alojada em um sistema democrático ou tirânico. Quando o filósofo põe as mulheres na arena política, ele não pretende com isso dizer o que são as mulheres, tampouco determinar um ethos feminino. Não se pretende reordenar os papéis de gênero na pólis, pois isso presumiria, de certo modo, um estabelecimento de identidades. 0 livro $\mathrm{V}$, sendo

16- De acordo com pesquisa liderada pela UNESCO - Atlas of Gender Inequality in Education (2016), em contexto global, são 16 milhões de meninas entre 6 e 11 que nunca frequentarão a escola. 
parte de um projeto mais amplo para a cidade, não comportaria os limites de códigos rígidos de atos performativos de gênero, porém Platão faz questão de familiarizar seus interlocutores com a possibilidade de novos corpos na política.

Gláucon - São uma formosura os governantes que tu modelaste, como se fosses um estatuário, ó Sócrates!

Sócrates - E as governantas também, sem dúvida, ó Gláucon! (PLATÃO, 1949, 540c [PLATO, 1997, 540c]).

0 desvio da paródia à política, talvez, tenha ficado mais explícito com Platão do que com Eurípedes. Platão não apenas subverte a noção de quem são os sujeitos políticos, como faz emergir possibilidades fora da inteligibilidade do corpo político da pólis, ou seja, os "corpos frágeis" das mulheres despontam no seio da pólis.

Sócrates - E assim, da maneira mais rápida e mais simples, se estabelecerá o Estado e a constituição que dizíamos, fazendo com que ele seja feliz e que o povo em que se encontrar valha muito mais. (PLATÃO, 1949, 541a [PLATO, 1997, 541a]).

\section{Considerações finais}

A nossa proposta de análise de dois textos, de estilos diferentes, da Antiguidade Clássica, sob o prisma de uma teoria contemporânea mostra o quanto os textos antigos podem nos ajudar na compreensão de questões do nosso tempo. A compreensão da análise que iniciamos ocorre precisamente pela diferença marcante entre os gregos atenienses e nós relativamente ao entendimento das identidades de gênero e de suas representações sociais. Platão e Eurípedes elucidam bem o quanto as fronteiras entre o masculino e o feminino tanto na esfera da sexualidade quanto na da política são difusas e partem de um discurso político, como aponta hoje Butler, o qual busca conformar as possibilidades dos atos performativos de gênero a uma narrativa binária das identidades. Sem dúvida, os textos permitiram-nos um exercício de pensamento de outras possibilidades de configurações das relações de gênero.

Eurípedes, no teatro, apresentou quais configurações uma cidade pode ganhar a depender do ethos do governante. Assim, mostrou-nos uma pólis dominada por práticas políticas que segregavam e excluíam todas as formas de manifestação daquilo que não se reconhecia enquanto tradição dada pelo poder soberano. Platão, em seu sagaz estilo de fazer filosofia, envolve-nos no discurso, segundo o qual evidencia as arbitrariedades do costume. Ele ironiza a aceitação tácita à tradição. Propõe, dentro de uma obra política, um exercício de pensar as relações coletivas de formas diferentes, exercício esse de pensamento e de ação. Assim, Eurípedes e Platão agiram como um espírito desordenador das normas e costumes de seu tempo e contribuíram para sugerir a possibilidade de romper, em alguma medida, com as identidades atribuídas às mulheres. 


\section{Referências}

AGACINSKI, Sylviane. Politique des sexes. Paris: Seuil, 1998.

AGAMBEN, Giorgio. Homo Sacer: o poder soberano e a vida nua I. Tradução de Henrique Burigo. Belo Horizonte: UFMG, 2010.

ANNAS, Julia. Plato's republic and feminism. Philosophy, Cambridge, v. 51, n. 197, p. 307-321, 1976.

BEAUVOIR, Simone. 0 segundo sexo: os fatos e os mitos. Tradução de Sérgio Milliet. v. 1. Lisboa: Quetzal, 2015.

BEAUVOIR, Simone. The second sex. Translated by Constance Borde and Sheila Malovany-Chevallier. New York, Vintage Books, 2010.

BIANCHI, Emanuela. Receptacle/Chôra: figuring the errant feminine in Plato's Timaeus. Hypatia, New Jersey, v. 21, n. 4, p. 124-146, Autumn, 2006.

BLUESTONE, Natalie Harris. Women and the ideal society: Plato's republic and modern myths of gender. Oxford: Market House, 1987.

BUTLER, Judith. Bodies that matter: on the discursive limits of 'sex'. Great Britain: Routledge Classics, 2011.

BUTLER, Judith. Gender trouble: feminism and the subversion of dentity. New York: Routledge, 1999.

BUTLER, Judith. Problemas de gênero: feminismo e subversão da identidade. Tradução de Renato Aguiar. Rio de Janeiro: Civilização Brasileira, 2010.

BUTLER, Judith. Undoing gender. Abington: Oxfordshire: Routledge, 2004.

CAVARERO, Adriana. II pensiero femminista: un approccio teoretico. In: RESTAINO, Franco; CAVARERO, Adriana. Le filosofie femministe. Torino: Paravia, 1999. p. 78-115.

CAVARERO, Adriana. In spite of Plato: a feminist rewriting of ancient philosophy. Translated by Serena Anderlini-D'Onofrio and Áine O'Healy. Oxford: Polity Press, 1995.

CHODOROW, Nancy. The reproduction of mothering psychoanalysis and the sociology of gender. Berkeley: Los Angeles: London: University of California Press, 1979.

CORNELLI, Gabriele. Seduzindo Sócrates: retórica de gênero e política da memória no Alcebíades platônico. [S. I.: s. n.], 2013. (Coleção tradições: Layout 1).

DARAKI, Maria. Dionysos et la déesse terre. Paris: Flammarion, 1994.

EURÍPEDES. As Bacantes. Introdução, tradução e notas de Maria H. R. Pereira. Lisboa: Edições 70, 2011. 
EURIPIDES. The Bacchae. In: GRENE, David; LATTIMORE, Richmond (ed.) The complete Greek tragedies. Chicago: University of Chicago, 2013.

FAUSTO-STERLING, Anne. The five sexes: why male and female are not enough. The Sciences, New York, v. 33, p. 20-24, 1993.

FOUCAULT, Michel. 0 Nascimento da biopolítica. Tradução de Eduardo Brandão. São Paulo: Martins Fontes, 2008.

HUBBARD, Thomas K. (ed.). A companion to Greek and Roman sexualities. Oxford: Blackwell, 2014.

IRIGARAY, Luce. Sorcerer love: a reading of Plato's Symposium Diotima's speech. In: TUANA, Nancy. Feminist interpretation of Plato. Pennsylvania: Pennsylvania State University Press, 1994. p. 181-195.

KRISTEVA, Julia. Powers of horror. Translated by Leon S. Roudiez. New York: Columbia University Press, 1982.

LEÃO, Delfim Ferreira. In defense of medea: a legal approach to Euripides. Epetiris, v. 43, p. 9-26, 2011.

LESSA, Fábio. Mulheres de Atenas, Mélissa: do Gineceu à Agorá. Rio de Janeiro: Mauad X, 2010.

MBEMBE, Achille. Políticas da inimizade. Tradução de Marta Lança. Lisboa: Antígona, 2017.

MIKKOLA, Mari. The wrong of injustice: dehumanization and its role in feminist philosophy. New York: Oxford University Press, 2016.

PANAYOTOV, Stanimir. $\chi \omega ́ \boldsymbol{\rho} \boldsymbol{\alpha}$ : femininity and space in plato's timaeus. 2011 (Master Thesis) - Institute for Social Sciences and Humanities Research, Euro-Balkan, Skopje, 2011.

PLATÃO. República. Tradução e notas de Maria H. R. Pereira. Lisboa: Fundação Calouste Gulbenkian, 1949.

PLATO. Republic. In: COOPER, John (ed.). Complete works: Plato. Indianapolis: Hachett, 1997.

ROMILLY, Jacqueline. A tragédia grega. Tradução de Leonor Santa Bárbara. Lisboa: Edições 70, 1997.

RUBIN, Gayle. The traffic in women: notes on the 'political economy' of sex. In: RAYNA Reiter (ed.). Toward an Anthropology of Women. New York: Monthly Review Press, 1975. p. 157-210.

SANFORD, Stella. Plato and sex. Cambridge: Policy, 2010.

SCOTT, Joan. Gênero: uma categoria útil para a análise histórica. Tradução e revisão de Guacira Lopes Louro e Tomaz Tadeu da Silva. Educação \& Realidade, Porto Alegre, v. 20, n. 2, p. 71-99, 1995.

SISSA, Giulia. Filosofias do género: Platão, Aristóteles e a diferença dos sexos. Tradução de Maria Manuela M. S. e Alberto Couto. In: PERROT, Michéle; DUBY, Georges (org.). História das mulheres: a antiguidade. Porto: Afrontamento, 1990. p. 79-123. 
UNESCO. Atlas of gender inequality in education. [S. I.: s. n.], 2016. Disponível em: https://www. tellmaps.com/uis/gender/\#!/tellmap/78041830. Acesso em: 21 jan. 2018.

VLASTOS, Gregory. Was Plato a feminist? In: TUANA, Nancy. Feminist interpretation of Plato. Pennsylvania: Pennsylvania State University Press, 1994. p. 11-23.

VERNANT, Jean Pierre. Mito e sociedade na Grécia antiga. Tradução de Myrian Campello. Rio de Janeiro: José Olympio, 1992.

VIVEIROS DE CASTRO, Eduardo. Os pronomes cosmológicos e o perspectivismo ameríndio. Revista Mana, Rio de Janeiro, v. 2, n. 2, p. 115-144, 1996.

Recebido em: 14.07.2019

Revisado em: 22.10.2019

Aprovado em: 17.03 .2020

Vânia Silva é doutora pelo Centro de Estudos Clássicos e Humanísticos da Universidade de Coimbra.

Gabriele Cornelli é professor associado do Departamento de Filosofia da Universidade de Brasília (UnB). É docente permanente dos Programas de Pós-Graduação em Metafísica e em Bioética. Diretor da Cátedra UNESCO Archai sobre as Origens Plurais do Pensamento Ocidental da UnB. 